\title{
Selection of Celebrity Endorser and Purchase Intention: A New Model
}

\section{Mohammed Majeed}

\begin{abstract}
Effective advertising is crucial for the company in influencing their customers to buy their products. Since advertising is the primary way in which the company communicates with its customers, it is an area of significance for companies to focus on. In spite of numerous theoretical and empirical studies that examine celebrity endorsement on purchase intention, a more comprehensive model is required. It is in the light of this I developed Fit-for-Purpose comprising of identification, internalization and fitness dimensions, which are proposed to be strong predictors of purchase intention. The study was based on literature review. The researcher recommended and concluded that firms must keep in mind that celebrity endorsements cannot take the place of robust brand building processes. As a result, marketers should make sure that the brand being endorsed and the endorser (local or international, celebrity type, etc.) are a good match, so that the endorsements will positively influence customers' thinking processes and generate a positive impression.
\end{abstract}

Keyword: Advertising, Endorsement, Purchase Intention, celebrity

\section{INTRODUCTION}

Organizations have adopted innovative tactics to survive and gain a substantial market share in the current state of fierce rivalry (Keller 2016; Osei-Frimpong, Donkor, \& Owusu-Frimpong, 2019) by attempting to draw consumers' attention to marketing communications (Nichols \& Schumann 2012). Consumers have become increasingly knowledgeable and demanding of the firm's goods and services, which is at the core of the evolving nature of competition (Brodie et al. 2011; Seno \& Lukas 2007). In light of this, it has become commonplace for businesses to use celebrities to promote their brands in Ghana and elsewhere in an effort to encourage consumers to patronize their offerings.

Celebrity endorsement was thought to provide a distinct distinction in a market with a high concentration of local, regional, and foreign brands (Roll, 2006). Meanwhile, celebrity endorsement has become a global phenomenon, with businesses employing endorsers as part of their marketing outreach campaign to promote their corporate or brand reputation through several platforms, including both conventional and digital marketing media, and to inspire consumers to purchase (Jatto, 2013). The term source characteristics refers to the qualities that a celebrity should have in order to be considered worthy of the cause.

Manuscript received on 10 March 2021 | Revised Manuscript received on 09 April 2021 | Manuscript Accepted on 15 April 2021 | Manuscript published on 30 April 2021.

* Correspondence Author

Mohammed Majeed*, Marketing Department, Tamale Technical University, Tamale ORCID: https://orcid.org/0000-0001-9804-5335 JEL COD: M31, Marketing tunteya14june@gmail.com

(C) The Authors. Published by Lattice Science Publication (LSP). This is an open access article under the CC-BY-NC-ND license (http://creativecommons.org/licenses/by-nc-nd/4.0/)
The source reputation theory and the source attractiveness theory provide a foundation for celebrity endorsement methodology, as well as an explanation of how the celebrity endorsement process affects consumers' minds. According to the source reputation theory, the celebrity's experience (expertise) and trustworthiness determine whether or not the message is accepted (Van der Waldt et al., 2009). Expertise refers to the source's perceived ability to make valid claims, while source trustworthiness refers to the source's perceived willingness to make valid assertions about the product (Ohaninan, 1990).

According to the Source Attractiveness Theory, which is based on social psychological science, message acceptance is determined by familiarity, likeability, and similarity (Van der Waldt et al., 2009). The term "familiarity" refers to the audience's understanding of the source as a result of exposure. Likeability is affection for the source's physical appearance and behavior, and resemblance of the source is the likeness between the source and the receiver (Jatto, 2013). In the sense of the effect of celebrity endorsement on customer purchasing intention, similarity, familiarity, and likeability have not been commonly evaluated in previous research studies.

Consumer purchasing intent was previously studied in terms of source reputation (Jatto, 2013). Branchik and Chowdhury (2017) go on to say that celebrity endorsers control endorsed goods and services because of their "talent, beauty, trustworthiness, and popularity." the source Consumer purchase intention is considered an attitude of the consumer, and characteristics of a celebrity can affect the consumer's attitude (Jatto, 2013). Previous research shows that expertness and trustworthiness have been explored in the context of purchase intention. As a result, it's reasonable to assume that all of the other variables would have an effect on purchasing intent.

The effectiveness of celebrity endorsement on customer buying intention has been limited to the United States (Zipporah, 2014), Europe (Jatto, 2014), and the Far East (Zipporah, 2014). (Hai-xia et al., 2015; Sharfina, 2015). On the contrary, there are few empirical research on the effects of celebrity endorsement on purchasing intent in Ghana. In terms of the Ghanaian background, research has been conducted to determine the effect of celebrity endorsement on cosmetic product brand equity (Sivesan, 2013). Celebrity endorsement can have a positive or negative impact on a person's buying decision, depending on three factors: credibility, attractiveness, and strength (Jatto, 2014). Source models are a way to draw attention to advertising without influencing purchase decisions.

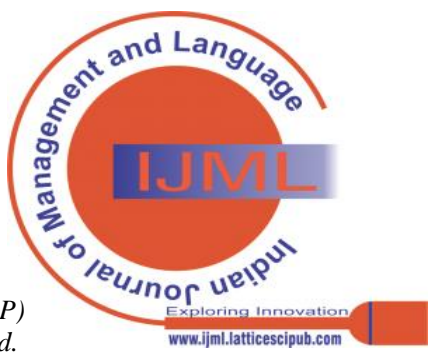


People are less influenced by beauty because of their strong brand association, and are more concerned with taste, consistency, and affiliation with the product (Hassan \& Jamil, 2014). Not every celebrity advertising campaign is successful. Because of the ineffective existence of the models used, some of them are very effective and others are not at all (Dissanayaka \& Ismail, 2015). In this field of study, current models such as source reputation and source attractiveness have been criticized (Bower and Landreth, 2001; Erdogan, 1999), and according to McCracken (1989), neither model can describe a match between a testimonial and a particular product in detail. Empirically, celebrity models including gratification (Sharfina, 2015), source reputation, and source attractiveness have not been shown to affect customer purchasing intention in most studies (Jatto, 2013), so theoretical depth is restricted (Bergkvist \& Zhou, 2016). To reduce the flaws associated with celebrity endorsement, a detailed new model must be created (Tellis, 1998). The researcher claims that there is a theoretical research void in relation to celebrity endorsement analysis and its effect on customer purchasing intention as a result of the previous models' flaws.

Till and Busler (1998) call for a more straightforward comparison of attractiveness and experience, as well as more empirical studies on the match-up hypothesis, since the authors found no evidence that certain dimensions were useful in the previous model. When it comes to matching celebrities to goods, Till and Busler (1998) argue that knowledge might be more important than attractiveness. The researchers also stress the significance of carefully selecting endorsers (Till and Busler, 1998; Ohanian, 1990). Furthermore, Till and Busler (1998) believe that competence, rather than attractiveness, is more fitting. The researcher follows the authors' call and closes this research gap by incorporating these hypotheses into the researcher's current conceptual model with the research design used in this study (mainly literature review).

The researcher looks at several dimensions, as well as different endorser characteristics and the environment, to resolve these calls and gaps. This research proposes a new model in which the dimensions of identity, internalization, and health are good predictors of purchase intent. The new model, which can be specifically checked for validation of celebrity traits as well as the method of selecting individual endorsers, is a one-of-a-kind model. This methodological paper can also assist managers in choosing only the right endorsers for their products by looking at a wide variety of countries with diverse cultures and competitive environments. This research is remarkable in that it is the first to present a new model. Three detailed measurements are used in this model. This model is needed to gain a better understanding of the attitudes and behaviors of consumers. It may assist in lowering risk and increasing overall message acceptance. If the source's credentials are viewed as being relevant to the product being endorsed, as in the case of the new model, the effectiveness of the endorser can be increased. Other concerns people can have to the endorser or the product can be resolved using this model.

Other sections of the papers capture literature comprising of theoretical framework, criticism of the previous model, mistakes in selecting a brand, how to address those mistakes, process of celebrity selection, discussion of the new model, discussions and conclusion.

\section{LITERATURE}

\section{Theoretical Considerations}

\section{Definitions of Celebrity Endorser}

Freiden (1984) presented the first concept of celebrity endorser, which included "well-known individuals who are closely affiliated with the product category being marketed." "Any person who enjoys public attention and who uses this recognition on behalf of a consumer product by appearing with it in an advertisement," according to McCracken (1989). Schlecht (2003) expanded on previous definitions, claiming that celebrities are people who are widely recognized by a large group of people, while attributes such as attractiveness and extraordinary lifestyle are only examples, and specific common characteristics cannot be observed, though it can be seen that celebrities generally differ from the general public within a corresponding social group. Although performing their careers as entertainers, sports stars, politicians, business executives, religious personalities, academicians, journalists, and others, it is obvious from the descriptions above that most celebrities draw a lot of publicity and appreciation from a wide range of people.

\section{Celebrity Endorsement}

Endorsement is characterized as any advertising message that customers are likely to believe represents the views, values, findings, or expertise of a party other than the sponsoring advertiser (including verbal statements, presentations, or depictions of the name, signature, likeness, or other identifying personal characteristics of an entity or the name or seal of an organization). In today's marketing, celebrity endorsement is a common occurrence (McCracken, 1989). Celebrities are often used to endorse products because they have a higher chance of attracting audience interest and influencing customer attitudes and buying intentions (Munnukka et al. 2016; Pradhan et al. 2016; Zhou \& Whitla 2013).

The spokesman, according to Kamen, Azhari, and Kragh (1975), serves as a kind of center around which the substantive messages are placed. There has been a large rise in the number of celebrity endorsements in recent years (Boyd \& Shank, 2004). Celebrities are a popular sight in today's marketplace, often serving as the face or image of not only consumer goods and brands, but also businesses (Illicic \& Webster, 2011). By partnering with a celebrity, a brand will capitalize on the celebrity's unique and positive secondary brand associations to increase market recognition, pass positive celebrity associations to the brand, create brand image, and eventually increase the endorsed brand's equity (Keller, 2008). Celebrities not only sell goods and brands; they also have a major impact on customer views and expectations across all aspects of popular culture and public life (Time Inc., 2006).

Although celebrity endorsement has not been thoroughly investigated in the Ghanaian context, there are an increasing number of celebrity-focused media outlets in Ghana, according to Agyepong (2017).

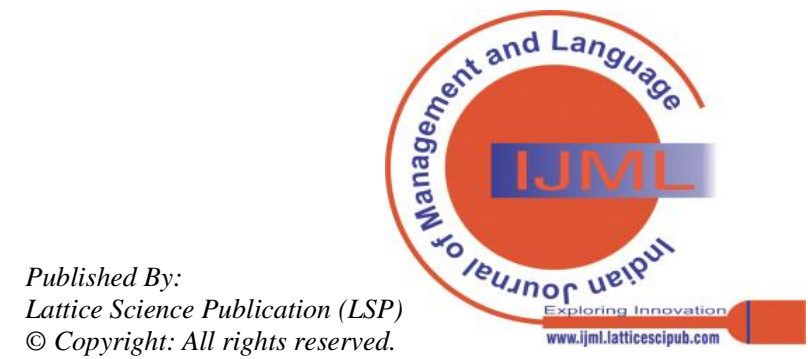


According to Agyepong (2017), celebrity is a general concept that lacks proper cultural, geographical, or demographic contextualization.

Corporations spend a lot of money to associate themselves and their products with big name celebrities in the hopes that they can (a) attract attention to the supported products/services and (b) pass image values to them because of their celebrity profile and engaging attributes (Erdogan 1999; Ohanian, 1991). The amount of advantages retailers have seen from using this type of advertising can be due to celebrity endorsement. Celebrities have the power to draw an audience's attention, offering retailers a greater chance of getting their message across to customers (Choi \& Rifon, 2007). Another advantage, according to Agrawal and Kamakura (1995), is when a celebrity is associated with a brand image and helps form the brand's image.

\section{Models of Celebrity endorsement}

\section{Source Credibility and Attractiveness}

Source credibility is a concept that refers to the positive attributes of a speaker that influence the receiver's recognition of a message (Ohanian, 1990). Celebrity endorsers' reputation is thought to be based on three factors: attractiveness, trustworthiness, and knowledge (Ohanian, 1990). The Source Credibility Model was first suggested by Hovland, Janis, and Kelley (1953), who argued that knowledge and trustworthiness were the two major components that influenced the credibility of the message sent by the source. The degree to which a communicator is regarded as a source of true claims about the object or problem is defined as expertise, and trustworthiness is defined as the degree of customer confidence in the communicator's intent to convey the assertions she or he believes are most valid.

The second model is attractiveness, which is based on a study by McGuire (2009). According to McGuire (2009), three important characteristics of a source are reputation, beauty, and strength. The source's perceived attractiveness is referred to as attractiveness. Physical attractiveness of a communicator is operationally characterized as the degree to which a person's face is pleasing to look at, and is decided by a panel of judges (Van der Waldt et al., 2009). In the sense of the source attractiveness model, three main factors stand out and contribute to the message's effectiveness. These are the endorser's familiarity, likeability, and similarity (McGruire, 2009).

\section{Criticism of the Celebrity Models}

This new model was created as a result of the flaws in these popular models. From both a theoretical and empirical standpoint, there have been many critiques of the current models. First and foremost, source models cannot be used to demonstrate the efficacy of a specific endorser for a specific product. As a result, it's hard to say why a celebrity works out with certain goods but not others. Furthermore, the source models do not have a useful tool for distinguishing celebrities. McCracken (1989) proposes that celebrity endorsements should be viewed as part of a three-step meaning transfer procedure.

Since the models are built on and mirror social influence theory, which states that certain features of a source in any communication can influence message receptiveness, the source models are only grouped under the same name
(Erdogan, 1999). The product match-up hypothesis has a flaw that is essential for organizations when selecting the right endorser; it is ineffective as a model because it does not define or quantify measurements that are relevant to a particular product. As a result, as previously said, it is better used as a complement to the other, more comprehensive ones (Erdogan, 1999; Hunter, 2010). As a result, results support the idea that celebrities represent concepts that are passed on to brands via endorsement. It forces advertisers to investigate the meanings of celebrities and choose the celebrity whose meanings correspond to the brand's desired meanings (McCracken, 1989; Erdogan, 1999), making it difficult to implement. There is still no guiding principle for selecting endorsers, which the new model would introduce. The researcher attempts to supplement current hypotheses with this proposed model in view of these differences.

\section{Source Attractiveness}

Both source models illustrate why and how celebrity endorsement works from the source's perspective, but they lack the connection with the endorsed product's target customers. They claim that the celebrity's personal characteristics have the potential to affect consumers' attitudes and behaviour. As a result, some scholars (see below) attempted to develop models from a more detailed perspective, taking target consumers' perceptions into account. Furthermore, source attractiveness models do not have a useful tool for distinguishing celebrities. McCraken (1989) and Basu (2009) propose the meaning transfer model as a solution, which consists of three phases that demonstrate the transfer of characteristics or meanings.

\section{Source Credibility Model}

The source credibility model has limitations, as it has been proposed that if customers have a favorable attitude toward an advertisement, a less reliable source may be more convincing than a more credible source (Erdogan, 1999; Harmon \& Coney, 1982; Sternthal et al., 1978). In other words, consumers' perceptions of an endorser's reputation can be easily swayed and then dictated by their possible affinity for the endorsed product. Furthermore, psychologists have discovered that many of the recipients of advertising messages are emotional and habitual. They lack the rationality and patience to learn more about the reputation of both the celebrity endorser and the endorsed product. And it is because of this phenomenon that the attractiveness trait stands out. As a result, the idea of source reputation model, which provides the survival soil for source attractiveness model, needs to be augmented to some extent. Erdogan (1999) goes on to say that, while source reputation has a direct and substantial impact on behavioral intentions and attitudes, and it is crucial for marketers to consider when choosing endorsers, it is not the only factor to consider. McCracken (1989) adds to this by arguing that there are far more influential variables than just attractive and reputable people, attacking all source models in the process. His thoughts on the most relevant driving factors will be addressed later.

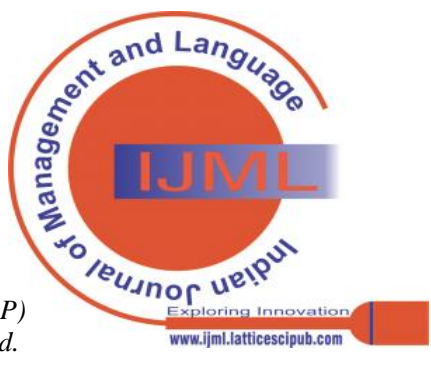




\section{The Meaning transfer model}

McCraken (1988) criticized the meaning transfer model for failing to depict all of the factors that influence communication effectiveness, claiming that it is difficult to know why a celebrity works out for certain goods but not others. Furthermore, as compared to the models above, it does not take all factors into account (Erdogan, 1999).

\section{Match up-Hypothesis model}

Celebrities, according to Dholakia (2018), are at risk of poor behavior and have too many brand affiliations. Liu (2005) investigated the impact of celebrities on product match-ups and found that only a high match between a product and a celebrity has a positive influence on producing more purchase intentions as compared to a low celebrity product match, and that celebrity attractiveness is not statistically important in influencing subjects' purchase intentions. The model's flaw is that it can't identify or quantify celebrity traits that are essential for specific product categories or brands. Choi \& Nora (2005), Braustein \& Zhang (2005), Ohanian (1991), and Kahle \& Homer (1985) found that endorser-product match is positively linked to customer attitudes and purchasing intentions in several studies.

Since it does not define or quantify measurements that are valid for a particular product, Match-up is restricted as a model. As a result, as previously said, it is better used as a complement to the other, more comprehensive ones (Erdogan, 1999; Hunter, 2010). Consumers, on the other hand, are not taken into account in this model. Consumers' attitudes toward the advertising, product, and brand matter the most as the final target of celebrity endorsement.

\section{Q Rating Technique}

Only the celebrity's familiarity and popularity are considered in the "Q" rating technique. The "Q" rating technique is simple to use and analyze statistically, but it is insufficient to determine which celebrity should be chosen.

\section{Mistakes for Brands to Avoid When Choosing a Celebrity Endorser}

Choosing a celebrity partner is a high-stakes, highreward gamble. A brand's reputation and market perception can be tarnished by the wrong celebrity partner. However, if the celebrity is chosen wisely, it can improve the brand's reputation, increase appeal with target buyers, and even shift the brand's trajectory. Brands also take a subjective approach to these decisions. We all have prejudices, but a multibillion-dollar plan should not be defined by them. Here are five popular blunders made by brands when selecting a celebrity to endorse them.

\section{Falling victim to internal bias}

The celebrity selection process always starts with the brand team sitting around a table discussing celebrities they like and meet, as well as celebrities their children or spouses enjoy. This is never more evident than in companies whose marketing departments are predominantly made up of older men who are obviously investing in celebrities who are primarily relevant to older men. Instead, it's crucial to think about what people who look like the brand's target customers think.

\section{Relying on vanity metrics}

Marketers often believe they are selecting celebrity talent with rigor, but in fact, they are just scratching the surface in terms of metrics. The size of a celebrity's social following is one measure that is frequently examined. However, just because a celebrity has millions of followers doesn't mean they're still relevant (those followers may have been acquired years ago), and it doesn't mean the brand can tell if the celebrity is on the rise. Marketers might often select celebrities because they have recently generated buzz about them, such as when they appeared in a blockbuster film or released a new album. However, headline publicity does not assist a brand in determining whether or not the celebrity is a good long-term fit. It's crucial to figure out which types of customers like the celebrity and whether or not they look like the brand's target demographic.

\section{Assuming your creative agency has it covered}

When it comes to selecting a celebrity endorser, brands also depend on their creative agency to be more thorough. In reality, creative agencies fall prey to internal bias, sit around a table thinking of celebrities they know and like, and rely on vanity metrics, just as a brand would. Even if the talent isn't exactly the right fit for your company, it's normal for a brand's agency partners to choose celebrities with whom they've already worked or to depend on pre-existing relationships with celebrities with whom they know they will possibly sign. To make sure the agency partners aren't firing from the hip, ask them how they came up with the celebrity suggestion.

\section{Blindly trusting talent agency recommendations}

When looking for celebrity endorsers, brands will also switch to talent agents or talent brokers. The problem is that talent agents and brokers exist to serve celebrities, so they aren't always suggesting clients based on their brand alignment. It's in their best interests because they'll get paid at the end of the day. If you ever plan to work with a talent agent or broker, you can ask them the following two questions: Do you ever make recommendations for those you don't represent? Can you get paid if this contract is signed? You will want to look elsewhere if they say no to the first and yes to the second.

\section{Not fully considering the celebrity's risk}

Not only does a previous conviction or drug and alcoholrelated events put a celebrity at risk, but so do other scandals and controversies. Politically or racially motivated material, as well as political leanings (liberal or conservative), may all turn off a certain percentage of your consumer base. Purchasing disgrace insurance, a financial insurance policy designed to cover the brand in the event of a celebrity scandal, is one of the best practices. Disgrace insurance, on the other hand, would only be useful if a damaging scandal emerges.

The celebrity selection process should not be delegated to a single marketer or even an entire marketing team due to the extremely subjective nature of celebrity decisionmaking.

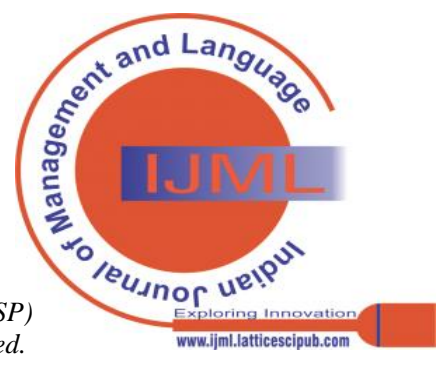


Rather, companies should invest in celebrities that target customers like, trust, and relate to. It's not trendy to be anything other than data-driven, says MIT Sloan lecturer Miro Kazakoff. Top executives who want to keep their jobs aren't going to say they manage by instinct."

\section{Methods used to reduce risks associated with celebrity endorsement}

According to Tellis (1998), there are many ways for businesses to avoid some of the potential pitfalls that may arise by using celebrity endorsers. Companies should begin by thoroughly screening applicants to ensure that they are purchasing the correct image and that the risk of a celebrity contract is worth the risk of possible harm. Companies may also include a moral clause in their contracts. A moral clause is a legal statement that offers businesses the option of terminating a contract for a partial or no charge. These often claim that if the celebrity is involved in some situation or incident that, in the company's fair opinion, exposes Talent or Company to criticism, contempt, or scandal, the company will terminate the contract (Tellis, 1998). Till (1998) goes on to say that in order to manage celebrity endorsers, businesses must create a bond between the endorser and the brand or product. When a connection is established between the celebrity and the brand, both become part of the association package, which is a collection of concepts that are meaningfully linked to the target brand. Consumers who think of Michael Jordan are a clear example of this. The associative learning mechanism relies on the repeated pairing of the two stimuli since it increases belief that the presence of one stimulus predicts the presence of the other stimulus. According to Till (1998), a single-minded approach to communicating the brand-celebrity pairing is the best way to reduce the chances of overshadowing the commercial executions. The ad's two most powerful factors should be the brand and the celebrity. Ad executions that are cluttered with unnecessary execution devices detract from the brand celebrity pairing, reducing the celebrity endorser's power. When there are few other competing elements in the commercial, the probability of establishing an associative relation between the celebrity and the brand increases (Till, 1998). Companies should use celebrity endorsement more often to reduce the possibility of extinction. Since it is impractical to expect a celebrity endorser image to appear any time a customer interacts with a brand. As a result, businesses should try to better incorporate endorsers into the marketing mix. Celebrity endorsers are most often used in advertisements, but they may also be effective in promotional events such as giving away related products or vacations that are related to the celebrity. Wide trade shows, national sales meetings, and other important marketing activities should all feature the celebrity (Till, 1998). There is a problem with financial risk. Companies must assess how cost-effective their celebrity option is. Frequently, the most valuable celebrity is often the most expensive. Companies should also seek out a lesser-known figure that matches the brand's message and appeals to the target market (Tellis, 1998). Finally, companies may use questionnaires (Q) scores to reduce the risks associated with celebrity endorsement. Shimp (1997) emphasized that in order to determine the effectiveness of a celebrity endorser, questionnaires must be created and circulated to individuals who must answer two basic questions: If you know who this star is? The second question is: if you have, how would you rate him or her? Would you rate him or her as bad, fair, decent, very good, or one of your favorites? According to Sandin and Widmark (2005), a celebrity might not be widely known, but he or she may still achieve a high $\mathrm{Q}-$ rating if one person who does remember the celebrity also likes the celebrity. A celebrity, on the other hand, may be well-known but still receive a low $\mathrm{Q}$ - rating because the respondents dislike them. Q-ratings are thought to be a smart way for businesses to stop recruiting major personalities who aren't well-liked by their target audience (Rossiter \& Percy, 1987). In the end, the use of Q -ratings to reduce the risks associated with celebrity endorsement in the industry can be concluded that the $\mathrm{Q}$-rating is an efficient method of filtering and shortlisting celebrities for a business.

\section{Endorser selection process}

The general presumption seems to be that a creative agency, possibly specializing in endorsements, handles or at least guides the majority of the endorser selection process. This assumption has surfaced in casual conversations with (inexperienced) marketing managers over the years. The lack of research on the overall selection process, which has yet to be completed or written, adds to this presumption (Erdogan \& Drollinger, 2008). The only existing literature on the method of endorser selection focuses on processes within advertising agencies. Erdogan and Drollinger (2008) published a groundbreaking report in 2008 on the mechanism by which advertising agencies pick endorsers. Given the breadth and depth of this research, it can be considered a ground-breaking achievement in the field of endorser selection research. Companies should be on the lookout for young celebrities who show promise and potential, and sign them on when they are still in their formative years if possible, to ensure a win-win situation.

\section{Celebrity Selection Process}

1. Company decides to carry out a celebrity led endorsement campaign.

2. Company's marketing focuses on a particular candidate from the start who is being directly contacted or via his agent.

3. Negotiations are carried out with celebrity (and his agent) and the endorsement contract between company and celebrity is signed.

Erdogan and Drollinger (2008) developed a normative model of the selection process, shall be introduced briefly in the following:

1. Company's marketing staff requests a campaign achieving certain goals with its advertising agency.

2. Agencies' teams discuss and evaluate various campaigns and finally move ahead with a celebrity-led campaign.

3. Market research is carried out to find appropriate candidates.

4. Agency gets in touch with pre-selected celebrities to clarify pre-conditions.

5. Agency proposes the campaign to its client.

6. After client's approval final negotiations are conducted, which usually take place among company staff, agency staff and celebrity's staff.

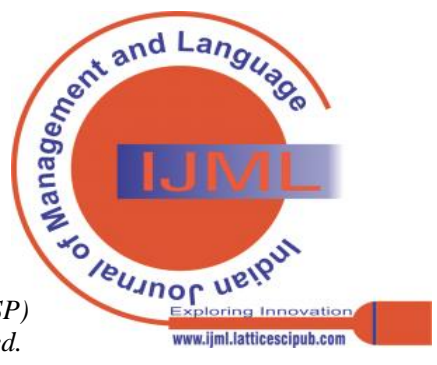




\section{A Theoretical Framework/Model}

\section{New model of celebrity endorsement}

\section{Fit-for-Purpose Model}

A Fit-for-Purpose Model is focused on electing a good celebrity for an advertising campaign. The theory proposes components that determine suitability, appearance and believability in a brand ambassador. In this case at all times, there is rich association (in terms of "fit") between celebrity endorser and the brand. Studies underline the fact that besides the brand that is the subject matter of the ad, and the integrity and appeal of the celebrity starring in the ad, there should be a match between the brand and the celebrity. In order for the credibility of the celebrity to increase and have a favourable impact on the brand in question, there should be a congruence, a "match", and a "fit" between the product being endorsed and the credibility of the celebrity; moreover, there must be congruence or fit between the product and the celebrity in terms of characteristics such as image, expertise or attractiveness (Agrawal \& Kamakura, 1995; Till \& Busler, 2000). In this model the company focuses on a celebrity-led endorsement campaign right from the beginning. This model is based on three principles:

1. The principle of process

2. The principle of environment

3. The principle of characteristics

\section{The principle of process}

The principle of process means the choice of a celebrity should not be by the mere discretion of management but systematic and procedural. Normally, the firm's marketing officers would have a desired endorser in mind from the onset. Advertising agencies are not involved in making the decision to pursue an endorsement campaign nor are they consulted to find suitable spokesmen. Due to the company's initial focus on a particular individual no evaluation process is in place which would vet a pre-selection of candidates ensuring a proper brand-endorser fit. Characteristic for this approach is also a rather high involvement of the celebrity who is present at most negotiations and in direct contact with the company. Sometimes agents might not be involved at all, limiting the parties participating in the process to company and celebrity.

\section{The principle of environment}

The principle of environment means celebrity should be chosen base on whether the celebrity is known to the target customers. There are types of endorsers such as global, regional, and national stars. There is also music, media featured, movie, athletic and charismatic personalities who endorse products. So, if the goal is to market a brand locally then his/her environment is Ghana (Jackie Appiah or KSM is local personality). Also, the celebrity's area of specialization matters so such in determining what brand to advertise.

\section{The principle of characteristics}

The theory of characteristics applies to the characteristics that a celebrity possesses that have the greatest effect on the target audience (Subhadip, 2012). It also has to do with whether or not he or she is the best person to promote the brand. The more these expectations are met, the more likely a communicator would have a positive impact on purchasing intent, and vice versa. The best "fit" will be achieved by effectively balancing celebrities' strategies in terms of their fitting qualities and characteristics with brand attributes placed in the minds of target buyers. Companies who hire celebrities to endorse their goods or brands will have a certain amount of positive results or outcomes if they find the best "fit." This idea makes use of theories such as the 'Source Credibility Theory' and the 'Source Attractiveness Theory,' which provide a basis for celebrity endorsement methodology and illustrate how the process of celebrity endorsement affects consumers' minds. The source credibility theory, proposed by Ohanian in 1990, states that when a source presents itself as reliable, people or receivers are more likely to be convinced (Hovland, Janis \& Kelly 1963). Actors/actresses, athletes, and other celebrities have all been used as spokespeople, according to Ohanian (1990). The Source Credibility Theory (Ohanian, 1990) may help understand why this happens. The three interrelated aspects of Source Attractiveness Theory have historically been regarded as Source Familiarity, Source Similarity, and Source Likeability. Researchers investigated which attributes of communicators are most effective for the target group's attitude toward change in order to aid marketing practitioners in their decision-making. The beauty and reputation of the message sender were discovered to be especially important characteristics (Solomon et al., 2006). These features, I believe, will have an effect on purchasing intent.

\section{Factor for Fit-for-Purpose Model}

This study proposes a new model that hypothesizes that factors such identification, internalization and fitness affect purchase intention.

\section{Identification Dimension}

Identification refer to physical characteristics, such as fashionable, similarity, familiarity, handsome / beautiful, and likability of a potential celebrity endorser.

\section{Fitness Dimension}

The matching of the personality type as a celebrity endorser with the attributes of a product is an important management belief for finding an appropriate celebrity endorser (Hou, 2012). For instance, a sport career celebrity (player) is most fitted for energy drinks or even foods in general. Also, a local endorser is accepted faster than a foreign one, unless he/she is a global brand celebrity. For instance, a Swiss celebrity may not impress Ghanaian customers.

\section{Internalization Dimension}

Internalization is the extent to which the receiver sees the source as having relevant expertise (knowledge, skills, experience) and trust to provide impartial and objective information. Information from celebrities can affect people's attitudes, beliefs, opinions, and/or their behaviour through a process known as internalisation.

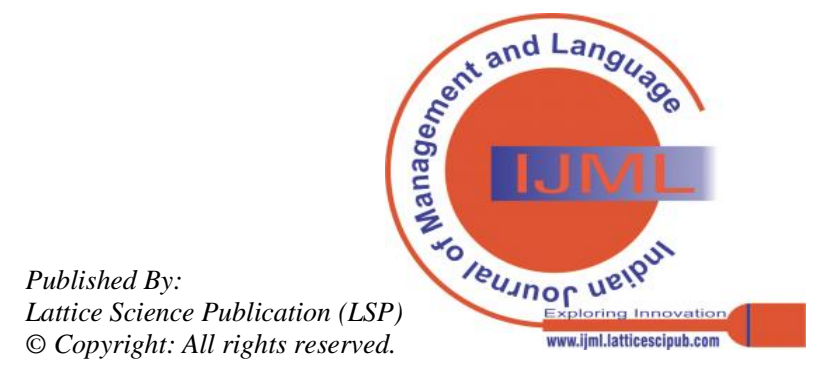


It arises when receivers (consumers), accept a source stimulus in terms of their personal attitude and value structures (Ulkhaq et al., 2016). Internalization which is liken to source credibility is used to imply a communicator's positive inward characteristics that will affect the receiver's acceptance of a message. Expertise is defined as the extent to which a communicator is perceived to be a source of valid assertions about the object.

Table 1: scales for future researchers

\begin{tabular}{l|l}
\hline Latent variable & Items \\
\hline Identification & $\begin{array}{l}\text { I prefer to watch advertisements with physically attractive (beautiful, elegant, classy) } \\
\text { endorsers } \\
\text { I think that attractiveness is an important characteristic for celebrity endorsers. } \\
\text { I feel that a physically attractive endorser influences my purchase intention towards a } \\
\text { celebrity endorsed brand. } \\
\text { I remember a brand that is endorsed by an attractive celebrity more. }\end{array}$ \\
\hline Internalization & $\begin{array}{l}\text { I pay more attention to advertisements using a celebrity with expertise. } \\
\text { I will buy a product if the celebrity endorsing it is an expert. } \\
\text { I think a brand being endorsed by a celebrity with expertise is more trustable. } \\
\text { I feel that an advertisement with a trustworthy endorser pushes me to remember that } \\
\text { advertisement } \\
\text { and the product that is being endorsed. } \\
\text { I prefer to buy a product if the celebrity endorser is a trustworthy person. } \\
\text { I think that a brand endorsed by a trustworthy celebrity is more respectable and } \\
\text { desirable. }\end{array}$ \\
\hline $\begin{array}{l}\text { His personality matches with the brand } \\
\text { The local endorsers are good for the product } \\
\text { The endorser career matches the brand }\end{array}$ \\
\hline Fitness
\end{tabular}

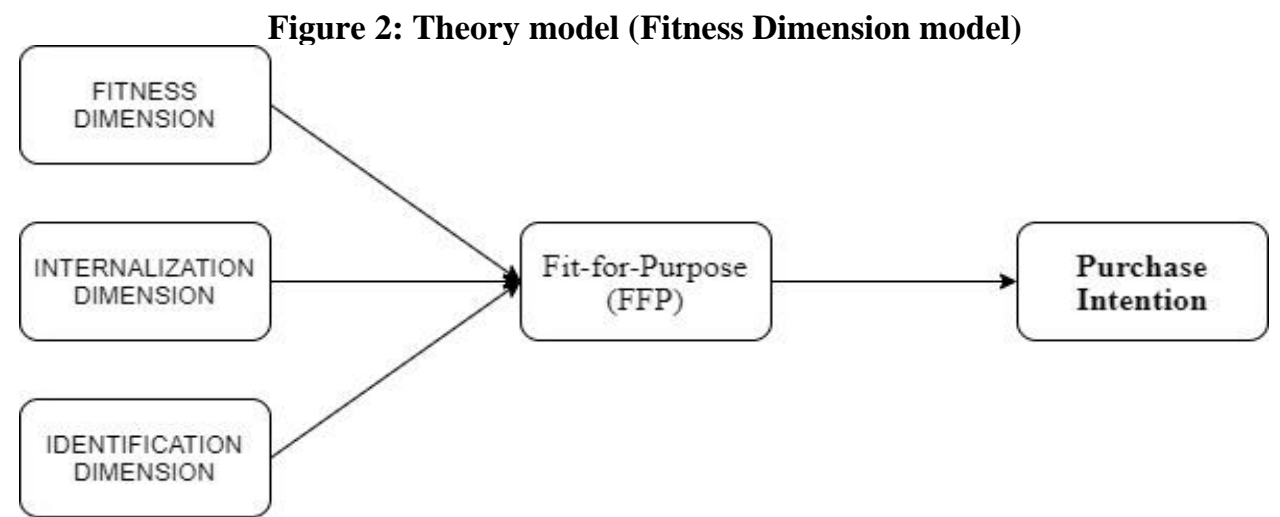

\section{Prepositions}

From the conceptual model proposed, the following prepositions are suggested:

$\mathrm{P}_{1}$ : Identification Dimension is positively related to customer purchase intention

$\mathrm{P}_{2}$ : Fitness Dimension is positively related to customer purchase intention

$\mathrm{P}_{3}$ : Internalization Dimension is positively related to customer purchase intention

\section{Achieving Suitability between Endorsers and the Endorsed Brands using Fit-for-Purpose Model}

It is important to match the celebrity with the characteristics of the product featured in the commercial to ensure credibility. Product-celebrity congruence (matching the characteristics of a celebrity endorser with the qualities of a product) has been emphasized by many researchers as an important management concept for identifying suitable celebrity endorsers (Seno and Lukas, 2007, Hou, 2012). According to the Fit-for-Purpose Model, celebrity endorsement is only successful if there is a complete connection between the celebrity and the endorsed brand
(Hsu \& McDonald, 2002). The Fit-for-Purpose Model is based on the assumption that the message expressed by the celebrity's image and the message about the product should meet in successful advertising, with a focus on the relationship between the celebrity and the endorsed brand. Marketers must ensure that the messages communicated by celebrity photos and product messages are congruent for successful advertisement in the Product Fit-for-Purpose Model. The degree of perceived 'fit' between brand (brand name, attributes) and celebrity image is also a determinant of suitability between the celebrity and the brand. In other words, it means that endorsers are most successful when the endorser and the endorsed brand / commodity are a good match (Biswas et al., 2006). It notes, to a large extent, that for an endorsement to be effective, the messages conveyed by a celebrity's image and the product's message must be uniformed and consistent. Three social mechanisms are responsible for celebrity endorsement's popularity.

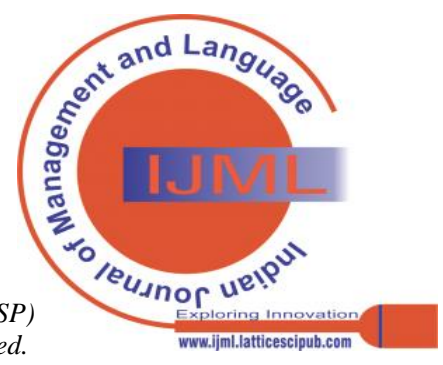


The first effect is identity, which means that customers imitate the behaviours and recommendations of celebrities because it makes them feel good to think they are like them. In this case, it can be further clarified that celebrity has a significant effect on consumer values, views, and desires. As a result, the customers are drawn to the celebrity. Internalization is the second social element, which implies that customers adopt others' attitudes or behaviours because they believe in the essence of the new attitude or behaviour (Friedman et al., 1979). Internalization is linked to the expert knowledge that an endorser possesses, making him or her a reliable source of the advertising message. Identification is thus linked to likeability and beauty, while internalization is linked to the expert knowledge that an endorser possesses, making him or her a credible source of the advertising message. When a customer internalizes a behaviour or attitude as a result of a celebrity's endorsement, the consumer may enforce or express it both publicly and privately. The third and final category is health, which happens when a customer acknowledges the endorser's or other consumers' power.

\section{DISCUSSION}

Firms would have to decide whether or not to use celebrity endorsers, and if so, how they should go about doing so. Previous empirical study, which usually looked at just a few cases, has shown mixed results, causing more uncertainty than guidance for managers (McCall \& Voorhees, 2010). To resolve this uncertainty, the researcher proposed this model and encouraged other researchers to test whether consumer purchasing intentions are influenced by I celebrity characteristics (identifying), (ii) internalizing, and (iii) brand, country, and brand characteristics (fitness). As a result, the researcher discusses the problem of theory gab, in which several studies have found that elements in current theories do not lead to buying intentions. Using the model developed by this study, advertising agencies or other manufacturing/service companies may gain a deeper understanding of customer perceptions of celebrity advertising. Overall, businesses can choose which form of celebrity endorser is best for their products.

\section{Management Implication}

Consumers are more likely to trust information from a communicator or celebrity with whom they share goals, desires, or a way of life than information from someone with whom they do not. Celebrities are often thought to have the potential to shift their image to a specific product being promoted. The concepts and dimensions of this new model should be closely examined by management in order to avoid making errors when selecting a celebrity endorser. Processes, climate, and attributes, as well as health, internalization, and identity measurements, are all included in the principles, which provide a great management guide for successful endorser selection and efficient ads. The following advantages are guaranteed if the model is used correctly. It will help advertisers stand out from the crowd and attract attention. They're also thought to be more fun and trustworthy. Furthermore, celebrity image has an impact on brand image, which aids the marketing manager in launching a new product or repositioning an existing one. The new celebrity model, which has been well-planned, has the potential to shift negative attitudes toward branded brands. The right celebrity choice can help create a position for a newly introduced product as well as change perceptions about a brand that has been mispositioned. This model will assist in the use of celebrity endorsement to generate a positive impact on the firm's financial status.

\section{CONCLUSION}

Companies must keep in mind that celebrity endorsements cannot take the place of robust brand building processes. As a result, marketers should ensure that the brand being endorsed and the endorser (local or international, celebrity type, etc.) are compatible so that the endorsements will positively impact consumers' thought processes and generate a favourable view of the brand in their minds. The idea to create a marketing plan around a celebrity could come from a seasoned design agency that has been tasked with devising a campaign that meets specific goals. However, the decision to follow such a strategy could come progressively and internally, when a specific personality has piqued the interest of marketing staff over time. Furthermore, the method of selecting a specific person tends to be complex.

\section{REFERENCES}

1. Agrawal, J., and Kamakura, W. A. (1995). The Economic Worth of Celebrity Endorsers: AnEvent Study Analysis. Journal of Marketing, 59 (7), 56-62 [CrossRef]

2. Biswas, D., Biswas, A and Das, N. (2006). The differential effects of celebrity and export endorsements on consumer risk perceptions. Journal of Advertising, 35 (2),17-31 [CrossRef]

3. Dissanayake, D. M., \& Semasinghe, D. M. (2015). Is culture a restraining or a driving force for entrepreneurship in Sri Lanka? African Journal of History and Culture, 8-15. [CrossRef]

4. Friedman, H. H., and Friedman, L. (1978). Does the celebrity endorser's image spill over the product? Journal of the Academy of Marketing Science 6, 291-299 [CrossRef]

5. Janet, C. (2018). Mistakes for brands to avoid when choosing a celebrity endorser. Brand Marketing, 27(9), 3-6 [CrossRef]

6. Hsu, C., and McDonald, D. (2002). An examination on multiple celebrity endorsers in advertising. Journal of Product and Brand management, 11(1), 19-29. [CrossRef]

7. Ohanian, R. (1990). Construction and Validation of a Scale to Measure Celebrity Endorsers' Perceived Expertise, Trustworthiness, and Attractiveness. Journal of Advertising, 19(3), 39-52. [CrossRef]

8. Till, B. D. and Busler, M. (2000). The Fit-for-Purpose Model: Physical attractiveness, expertise and the role of fit on brand attitude, purchase intent and brand beliefs. Journal of Advertising, 29(3), 1-13 [CrossRef]

9. Choi, S. M., Rifon, N. J. (2007). Who is the celebrity in advertising? Understanding dimensions of celebrity images. Journal of Popular Culture, 40(2), 304-25. [CrossRef]

10. Dissanayake, D. M., \& Semasinghe, D. M. (2015). Is culture a restraining or a driving force for entrepreneurship in Sri Lanka? African Journal of History and Culture, 8-15. [CrossRef]

11. Erdogan, Z. and Drollinger, T. (2008). Endorsement practice: how agencies select spokespeople. Journal of Advertising Research, 48(4), 573-82. [CrossRef]

12. McCracken, G. (1989). Who is the celebrity endorser? Cultural foundations of theendorsement process. Journal of Consumer Research, 16(3), 310-321 [CrossRef]

13. Forouhandeh, F., Nejatian, B., Ramanathan, G., and Forouhandeh, H. (2011). The Benefit oSocial media: Buleting Board focus as a tool for co-creation. International Journal ofMarketResearch, 55(6), 809-821. [CrossRef]

14. Hovland, C., Janis, I., \& Kelley, H. (1953). Communication and Persuasion. New Haven, GT: Yale University Press.

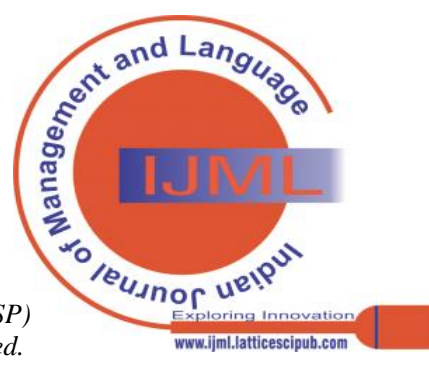


15. Freiden, J. B. (1984). Advertising Spokesperson Effects: An Examination of Endorser Type and Gender on Two Audiences. Journal of Advertising Research, 24(11), 33-41

16. McCracken G. (1989). Who is the celebrity endorser? Cultural foundations of the endorsement process. Journal of Consumer Research, 16(3): 310-321. [CrossRef]

17. Jatto, O. (2013). Consumer Attitude towards Celebrity Endorsements on Social Media. Dissertation , Univeristy of Dublin, Dublin Business School.

18. Keller, K. (2008). Strategic Brand Management: Building, Measuring, and Managing Brand Equity, (3rd ed). Prentice Hall, Upper Saddle River, NJ

19. Roll, M. (2005). Asian Brand Strategy: How Asia Builds Strong Brands. Palgrave Macmillan, Basingstoke.

20. Rossiter, J. R., and Percy, L. (1987). Advertising, and Promotion Management. London: McGraw-Hill Inc., ISBN 0-07053907-3

21. Shimp TE (1997). Advertising, Promotion and Supplemental Aspects of Integrated Marketing Communication, $4^{\text {th }}$ ed., Forth - Worth: The Dryden Press, ISBN 0-03-010352-5

22. Sandin, D. and Widmark, P. (2005). Celebrity Endorsement, Motives and Risks. A Case Study of Skanemejerier. Lulea University of Technology Bachelor Thesis.

23. Schlecht, C. (2003). Celebrities' impact on branding, Center on Global Brand Leadership.Columbia Business School. 15(5), 1-13.

24. Seno, D. and Lukas, B. A. (2007). The equity effect of product endorsement by celebrities: a conceptual framework from a cobranding perspective. European Journal of Marketing, 4(1/2), 121-34. [CrossRef]

25. Ohanian, R. (1990). Construction and Validation of a Scale to Measure Celebrity Endorsers' Perceived Expertise, Trustworthiness, and Attractiveness. Journal of Advertising, 9(3), 39-52. [CrossRef]

26. Ohanian, R. (1991). The impact of celebrity spokesperson's perceived image on consumerse intention to purchase. Journal of Advertising Research, 31 (1), 46-52

27. Solomon, M., Bamossy, G., Askegaard, S. and Hogg, M. K. (2006). Consumer Behaviour. Prentice Hall, Essex.

28. Hou, T. (2012). How Do Chinese Consumers Perceive Celebrity Endorsers: A Social Identity Perspective? A Thesis in the John Molson School of Business. Master of Science in Administration Program (Marketing Option) Master of Science in Administration at Concordia University, Montreal, Quebec, Canada

29. Hsu, C. and McDonald, D. (2002). An examination on multiple celebrity endorsers in advertising. Journal of Product and Brand management, 11(1), 19-29 [CrossRef]

30. Zipporah, M. M., \& Mberia, H. K. (2014). The Effects OF Celebrity Endorsement in Advertisements. International Journal of Academic Research in Economics and Management Sciences, 3(5), 178-188. [CrossRef]

\section{AUTHORS PROFILE}

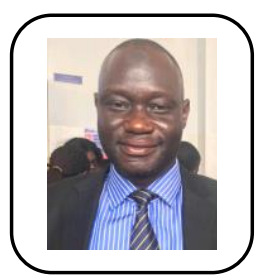

Mohammed Majeed (PhD), lectures at Tamale Technical University. He holds DBA, MPhil, MBA, PGD and HND Marketing. He has published about 20 articles so far.

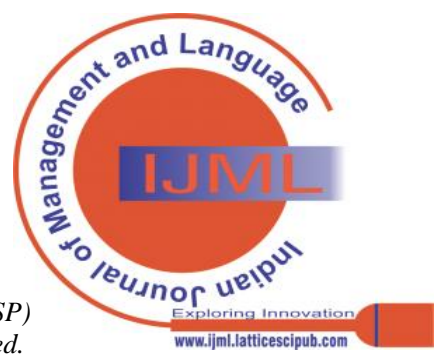

